much more easily relate effects to observations. In addition, all the interesting effects we are looking for are macroscopic effects. Classical microscopic calculations, like the one by Stevenson, are useful in testing model assumptions, such as the degree of thermal equilibration, but provide little insight into the collective properties of hundreds of nucleons. We need macroscopic models characterised by a few bulk parameters, such as the compressibility modulus, which are adjusted to experimental data in order to learn new new physics. For instance, for compression and re-expansion effects, some macroscopic calculations have just recently pointed out the effects which might be seen experimentally.

The data fitted by Stevenson were taken with a detector of small solid angle so that the experiment looked at only one particle from each event but accumulated data for many events. However, present experiments measure the multiplicity of charged particles associated with the particle in the main detector, and thus are able to select central collisions on the basis of their high multiplicities. Experiments that measure two particles in each event are in their early stages. These twoparticle correlation studies will give a much better indication of the degree of thermalisation, because in a single nucleon-nucleon scattering the two nucleons tend to be correlated at $180^{\text {? }}$ in the centre of mass, while in a thermal model they would be uncorrelated. The future lies in measuring as many of the final particles as possible in each event and thus determining the collective motion of the nucleons emitted. One hopes that one day it will be possible to relate data of this kind back to the equation of state of the compressed nuclear matter.

\section{Insects need cilia}

\section{from Michael Sleigh}

IT is generally agreed that arthropods lack water-propelling ciliary organelles of the $9+2$ pattern, except on the sperm of some members of the group. Recent observations by Bradley and Satir (J. Cell Sci. 35, 165; 1979) suggest that insects have found it necessary to develop alternative structures to perform the function of fluid propulsion or at least the transport of uric acid crystals, in the Malpighian tubules. The authors have named these structures axopods, by analogy with the stiff microtubule-supported pseudopodia of certain amoeboid protozoans, the Heliozoa and Radiolaria.

The axopods found in the lumen of
Malpighian tubules of the bug Rhodnius are branching projections occurring among, but longer than, the microvilli of the cells lining the lower tubule; they contain between 1 and about 50 microtubules and vary in thickness between about 0.2 and $0.8 \mu \mathrm{m}$. The microtubules are separate and regularly spaced, several diameters apart, but without any of the specific patterns or links found in protozoan axopods (Cachon \& Cachon Ann. Biol. 13, 523; 1974). Where the insect axopods branch, groups of microtubules separate and pass into each section. At the base of the axopod the microtubules extend deep into the cell to end near an inner cell boundary or in a cluster of mitochondria; no association has been found with a centriole or other microtubule-organising centre. Sections of the axopods reveal groups of longitudinal microfilaments close to the peripheral membrane.

It has not been possible to gain a clear view of the insect axopods in motion, but the movement of uric-acid crystals is consistent with propulsion by the axopods, and no other means of propulsion appear to be present in the experimental situation. The propulsive action is assumed to take the form of active lashing of the axopods. Analogous microtubular organelles other than cilia and flagella do not normally show this form of motion; the straight axopods of Heliozoa merely change their length to promote cell movement (Waters J. Cell Sci. 3, 231; 1968) and the haptonemata of certain flagellates, flagellum-like projections that contain a small number of single microtubules, perform coiling movements (Leadbeater J. mar. biol. Ass. U.K. 51, 207; 1971). The appendages of the marine protozoan Sticholonche may come nearest to insect. axopods, for the numerous, stiff, microtubular exopods of Sticholonche are pivoted at the base and are caused to perform rowing motions by the contraction of (non-actin) microfilaments attached to their bases (Cachon, Cachon, Tilney \& Tilney, J. Cell Biol. 72, 314; 1977). It seems likely that microvilli of insect malpighian tubules may have been invaded by microtubules; while these provide the stiffness necessary for the propulsion of fluid, the actual bending forces may be provided by microfilaments, as Bradley and Satir suggest. Fluid propulsion of a similar type has been observed in a number of other situations in arthropods; it will be interesting if similar forms of modified microvilli have been adopted elsewhere or whether true cilia do exist on epithelial cells of arthropods.

Michael Sleigh is Professor of Biology at the University of Southampton.

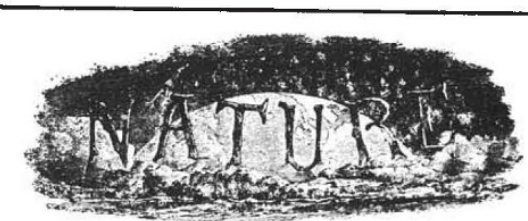

\section{A hundred years ago}

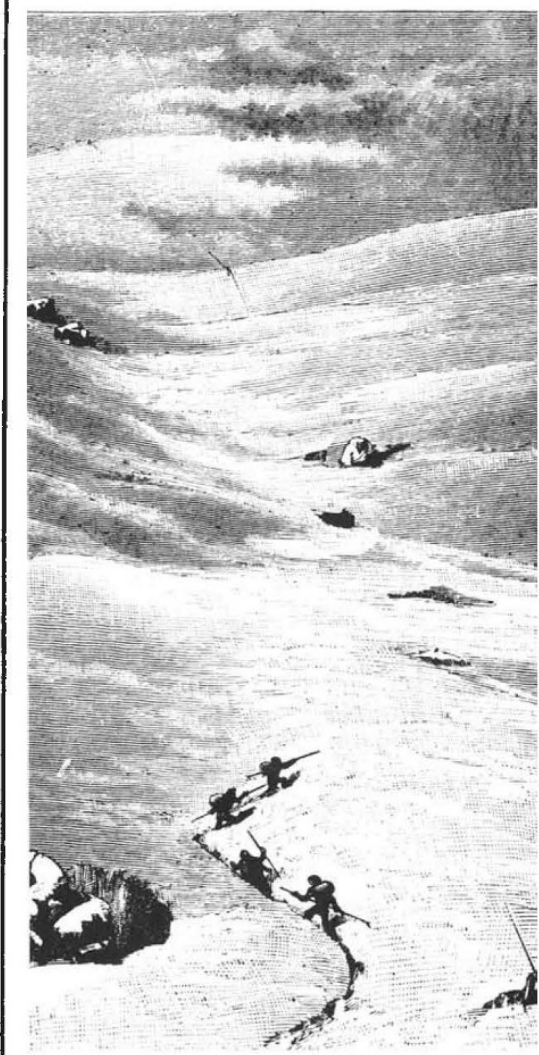

Oun readers may remember that early in the year General de Nansouty, the hardy director of the Pic du Midi Meteorological Observatory, was cut off from communication with the world below, the severe weather having so affected the telegraph as to prevent it from acting. Fears were entertained for the General's safety, and M. Albert Tissandier resolved to organise a party for the ascent of the Pic and the succour of the veteran observer. An interesting account of this ascent appears in La Nature, to which we are indebted for the accompanying illustrations. The snow-storm having somewhat abated at Bagnères-de-Bigorre on January $9, \mathbf{M}$. Tissandier resolved to attempt the Pic next day, in company with three of General Nansouty's usual guides.

They set out at 9 A.M. On the 10 th, and in spite of the deep snow and fallen avalanches, the ascent was at first not difficult. After equipping themselves for snow work at some huts occupied only in summer, the ascent was begun in earnest. The weather was grey and uncertain, the temperature $0{ }^{\circ} \mathrm{Cent}$., with a thick mist that prevented anything being seen beyond 300 metres. The snow became deeper and eeper as they advanced, and one of the guides went before to show the way, the others following the marks of his footsteps up the steep slope of the mountain side. Sometimes they were buried to the waist, and often they had to rest to recover breath.

From Nature 19, 27 February, 390; 1879. 